\title{
ANTIOXIDANT CAPACITY OF SOME PLANT FOODS AND BEVERAGES CONSUMED IN THE EASTERN REGION OF NIGERIA.
}

\author{
Gabriel A Agbor ${ }^{1,2}$, Philippe Moumbegna ${ }^{2}$, Eunice O. Oluwasola ${ }^{2}$, Lynda U Nwosu ${ }^{2}$, Rex- \\ Clovis C Njoku², Shelly Kanu ${ }^{2}$, Ephraim I Emekabasi ${ }^{2}$, Femi Akin ${ }^{2}$, Amarachi P Obasi ${ }^{2}$, \\ Florence A Abudei ${ }^{2}$
}

\author{
${ }^{1}$ Institute of Medical Research and Medicinal Plants Studies, P.O. Box 6163, Yaoundé Cameroon, \\ ${ }^{2}$ Department of Biochemistry, Faculty of Science, Madonna University, Elele, River State, Nigeria \\ *E-mail: agogae@yahoo.fr
}

\begin{abstract}
Today plant foods and beverages are receiving more scientific attention because of their potential to curb the effect of free radicals in the human system. The present study reports on the antioxidant potentials of some plants foods and beverages consumed in the Eastern Region of Nigeria. The study made use of the ferric reducing antioxidant power, phenolic and the flavonoid contents assays to assess the quality of the antioxidant potentials of the plant foods and beverages. Of the different classes of foods analyzed the following showed high antioxidant potentials: coffee for beverages, star apple for fruits, thyme for vegetable and spices, and raices for alcoholic beverages. Generally the vegetables and spices registered the highest antioxidant properties. The results obtained in this study could help consumers' choice based on the antioxidant capacity of the samples analyzed.
\end{abstract}

Keywords: Antioxidant, phenolic, ferric reducing antioxidant power, flavonoids, plant foods.

\section{Introduction}

Reactive oxygen species (ROS) are known to play a central role in the pathogenesis of degenerative diseases. They are involved in the oxidation of lipids, proteins, DNA damage and cellular degeneration related to cardiovascular disease (CVD), cancer, Alzheimer's and Parkinson's diseases (Clayson et al., 1994). These ROS are products of the system defense mechanism and normal metabolism. Current life style causes over production of free radicals and reactive oxygen species (Reddy et al., 2010). A well defined antioxidant system (enzymic and nonenzymic) coevolves with the aerobic metabolism to check the excesses of ROS (Niki et al., 1994). However, when the ROS overpowers the antioxidant defense, oxidative stress is eminent. Epidemiological studies have shown a convincing link between the antioxidant properties of plant derived polyphenolic compounds and their health promoting and disease preventing effect (Hollman et al., 1996, Kalt and Dufour 1997). Antioxidant compounds are found in plants with major defense mechanism against radical-mediated toxicity by preventing or attenuating the damages caused by reactive oxygen species (Farombi and Britton, 1999). The consumption of plant foods such as fruits and vegetables has been associated to a lower risk of degenerative diseases such as cancer, CVD, cataracts and immune dysfunction (Puttaraju et al., 2006). This protection is accounted for by the antioxidants in the plant foods (Collins, 2005).

Natural antioxidants protect from oxidative stress and associated diseases, therefore, play an important role in health care (Lopez et al., 2007). Plant foods (fruits, spices and vegetables) are important dietary sources of antioxidant polyphenols to humans (Vayalil, 2002; Agbor et al., 2005). There is a highly significant negative relationship between consumption of fruits and vegetables and ischemic heart diseases (Rimm et al., 1996). Fruits and vegetables are rich sources of vitamins ( $A, C$ and $E$ ), folates, carotenoides and dietary fibers. Fruits and vegetables are also rich in plants phytochemicals including flavonoids (antioxidant phytochemicals) (Agbor, 2009). Fruits and vegetables have been associated with prevention of obesity, lowering of plasma cholesterol, which is attributed to their fiber content, and reducing oxidative damage to biological molecules, enhancing immune responses, which are attributed to their antioxidant activity. Spices are food adjuncts used as flavoring, coloring, or seasoning agents. They are derived from barks (e.g., cinnamon) fruits (e.g., black pepper) and seeds (e.g., nutmeg). Several plant fruit, vegetables, and spices have been found to inhibit LDL oxidation in vitro by cupric ion and macrophages (Vinson et al., 1998; 2001a; 2005; DeWhalley et al., 1990; Mangiapane et al., 1992; Vinson et al., 1995a; Vinson et al 1995b; Agbor et al., 2010).

Traditionally, beverages include coffee, teas, red wine, beer, soda and cocoa products. However, today, fruit juices such as orange juice, pomegranate, guava, pineapple, apple juice, berry juices, which are rich in antioxidants, are bottled and ready to consume can also be classified as beverages. Of the traditional beverages, green teas, black teas, coffees, wine and cocoa are the most consumed worldwide followed by the pomegranates and the berries in the 
United States. These are rich in polyphenolic phytochemicals such as theaflavin, epigallocatechin gallate, resveratrol, procyanidin, chlorogenic acids, caffeic acids etc, which have potential chemopreventive action attributed to their strong antioxidant activities. In comparing their antioxidant activity, Lee (2003) observed that cocoa had more phenolic phytochemicals and a higher antioxidant capacity than teas and red wine. Today the potential health benefits of teas are been documented on a scientific basis. There is scientific evidence relating regular consumption of green tea to reduced incidence of a variety of cancers, and other diseases in USA and United Kingdom (Alexis et al., 1999; Balentine et al., 1997, Dreostic et al., 1997; Setiawan et al., 2001; Wang et al., 2000).

The present study is aimed at evaluating the antioxidant capacity of some plant foods and beverages consumed in Eastern Region of Nigeria (Ibos).

\section{Materials and Methods}

Reagents Used: Folin-Ciocalteu (Sigma), DPPH (Sigma), TPTZ (Sigma), Catechin (sigma), Ferric Chloride $(\mathrm{BDH}), \mathrm{HCl}(\mathrm{BDH})$, Acetic acid $(\mathrm{BDH})$, Sodium Acetate $(\mathrm{BDH})$. All reagents were of Analytical grade. All the samples i.e plant foods (Vegetables, Spices, fruits and breakfast cereals) and beverages (wines and beer) for analysis were bought from the Elele environ, Rivers State, Nigeria.

\section{Sample preparation}

Vegetables and Spices: The samples were cleaned and air dried at room temperature for 3 days. Samples were then blended to powder. $0.2 \mathrm{~g}$ of each sample was then dissolved in $10 \mathrm{ml}$ of distilled $\mathrm{H}_{2} \mathrm{O}$ and boiled for 90 mins with intermittent shaking after every 30 mins. This was allowed to cool and the volume adjusted to $10 \mathrm{ml}$ by addition of distilled water. The prepared extracts were then stored at $-20^{\circ} \mathrm{C}$ until analyzed.

Fruits: The fruits were cleaned and the peelings removed. The pulps each was blended and $9 \mathrm{~g}$ dissolved in $20 \mathrm{ml}$ distilled $\mathrm{H}_{2} \mathrm{O}$. This was then centrifuged and aliquots transferred in to vials stored at $-20^{\circ} \mathrm{C}$ until used.

Breakfast cereals: The breakfast cereals were prepared by dissolving $1 \mathrm{~g}$ sample into $15 \mathrm{ml}$ of distilled water and heated for $1 \mathrm{hr}$. After cooling, the sample volume was adjusted to $15 \mathrm{ml}$ and then centrifuged at 5000rpm. Supernatant was stored at $-20^{\circ} \mathrm{C}$.

Coffee, teas and cocoa products: The coffee and cocoa products were prepared according to the instruction on the label. That is $50 \mathrm{~g}$ (a sachet) sample dissolved in $270 \mathrm{ml}$ boiling water for 5 mins. The tea samples were prepared as described in the label i.e. $2 \mathrm{~g}$ dissolved in $270 \mathrm{ml}$ of boiling distilled water for 5 mins and allowed to cool. The supernatants of individual samples were collected and stored at $-20^{\circ} \mathrm{C}$ until used.

Wines and Beers: The wine and beer samples were analyzed directly from their bottles without any further treatment. All samples were analyzed in triplicate.

\section{Total phenolic content (TPC)}

The total phenolic concentration in the sample was measured using the Folin-Ciocalteu reagent (Sigma Chemical Co., St. Louis, MO) diluted 5 times to $0.4 \mathrm{~N}$ concentration (Vinson et al., 2001). The absorbance was measured at $750 \mathrm{~nm}$ after 10 mins of reaction with the aid of a spectrophotometer (Genesys Model 4001, Milton Roy Company, USA) and catechin (Sigma) used as standard.

\section{Total flavonoid content (TFC)}

Total flavonoid content of extracts was estimated using the aluminium chloride colorimetric method of Chang et al. (2002). Each plant extract $(0.5 \mathrm{ml}, 1 \mathrm{mg} / \mathrm{ml})$ in methanol was separately mixed with $0.1 \mathrm{ml}$ of $10 \% \mathrm{AlCl}_{3} \cdot 6 \mathrm{H}_{2} \mathrm{O}$, $0.1 \mathrm{ml}$ of NaCN and $2.8 \mathrm{ml}$ of distilled water. The absorbance of the reaction mixture was measured at $415 \mathrm{~nm}$ after 30 mins. Total flavonoid content was expressed as catechin equivalent.

\section{Ferric reducing antioxidant power}

The Ferric Reducing Antioxidant Power (FRAP) of extracts was determined as earlier described by Benzie and Strain (1996). The FRAP reagent consisted of ten part acetate buffer $(300 \mathrm{mM} \mathrm{pH} 3,6)$, one part of TPTZ (10mM in $400 \mathrm{mM}$ of $\mathrm{HCl}$, Sigma) and one part of ferric chloride $(10 \mathrm{mM})$. Catechin was used as the standard and absorbance read at $593 \mathrm{~nm}$. 


\section{Statistical Analysis}

Results are presented as Mean \pm Standard Deviation. Correlations between one method and the other were established using the Pearson Product Moment Correlation analysis at 95\% significance level $(P<0.05)$. The SigmaStat (Systat software, Richmond, CA) version 3.01 was used for this analysis.

Table 1. Fruits and alcoholic beverages analyzed

\begin{tabular}{|l|l|}
\hline Common/native name & Botanical name \\
\hline Banana & Musa acuminate \\
\hline Orange & Citrus sinensis \\
\hline Lime & Citrus aurantifolia \\
\hline Cucumber & Cucumis sativus \\
\hline Avocado & Persea americanum \\
\hline Mango & Magnifera indica \\
\hline Pineapple & Ananas comosus \\
\hline Star apple & Chrysophyllum africanum \\
\hline Pawpaw & Asiminia trilobia \\
\hline Brand names of beers and wines & Origin \\
\hline BARON DE TENA & Spain \\
\hline CASTILLO DE LIRIA & Spain \\
\hline CUVEE SPECIALE & Spain \\
\hline RAICES & Spain \\
\hline VINO TINTO & Spain \\
\hline STAR & Nigerian Breweries \\
\hline SMIRNOFF ICE & Guinness Nigeria \\
\hline GUINESS & Guinness Nigeria \\
\hline GORDON SRARK & Guinness Nigeria \\
\hline GULDER & Guinness Nigeria \\
\hline
\end{tabular}

Table 2. List of vegetable and spices analyzed

\begin{tabular}{|l|l|l|}
\hline Vegetables and spices & Botanical name & Uses \\
\hline Uha (ora) & Pterocarpus sovauxil & Preparation of local soup \\
\hline Green (inine) & Amaranthus viridis & Preparation of yam porridge and soup \\
\hline Ugu (pumpkin leaf) & Telferia occidentalis & For soup preparation \\
\hline Uziza (Uziza) & Piper guineensis & Soup preparation and flavorant \\
\hline scent leaf (nchuanwu) & Ocimum gratissimum & Spice in food and medicinal \\
\hline bitter leaf (onugbu) & Vernonia amygdelina & Soup preparation and medicinal \\
\hline $\begin{array}{l}\text { Garden Egg leaf (Akwukwo } \\
\text { anara, afufa) }\end{array}$ & Solanum spp & Soup preparation \\
\hline Ukazi (ukazi) & Gnetum bulchozianum & Soup preparation \\
\hline Onions & Allium cepa & $\begin{array}{l}\text { Widely used for cooking, add flavor to dishes } \\
\text { like stews, roasts, soups, salads, and frying. }\end{array}$ \\
\hline Garlic & Allium sativum & $\begin{array}{l}\text { Used either dried or ground to flavor tomatoes } \\
\text { sauces, stews, or salad dressing. }\end{array}$ \\
\hline Ginger & Zingiber officinale & $\begin{array}{l}\text { It is used dried and grounded to flavor bread, } \\
\text { sauces. }\end{array}$ \\
\hline Uda & Xylopia aethiopica & $\begin{array}{l}\text { Used for cooking and treatment of anal } \\
\text { cancer. }\end{array}$ \\
\hline Thyme & $\begin{array}{l}\text { Used dried to flavor fish, poultry, meats, } \\
\text { sauces, sausages. }\end{array}$ \\
\hline black pepper & Used in cooking. E.g. soup, pepper soup. \\
\hline
\end{tabular}

\section{Results and Discussion}

The role of free radicals has been implicated in several diseases such as liver cirrhosis, atherosclerosis, cancer, aging, diabetes etc (Halliwell and Gutteridge, 1985). Thus compounds that can scavenge these free radicals 
have a great potential to prevent or inhibit these diseases. Antioxidants are such compounds with radical scavenging activity. Different methods exist to assess the antioxidant potential of a compound or a substance. In the present study, we report on the antioxidant capacity of some sample fruits (9), teas (6), cocoa and coffee (7), breakfast cereals (8), vegetables and spices (10) and alcoholic beverages (10) as free polyphenol, flavonoid content and Ferric reducing antioxidant power (FRAP). Table 1-2 presents some of the different samples selected for analysis while the results are presented in Table 3-6. The samples presented different antioxidant capacities in relation to the methods of analysis and with respect of the different samples.

Table 3: Total Phenolic and Ferric Reducing Antioxidant Power (FRAP) (mg/g catechin equ.) of breakfast products

\begin{tabular}{|l|l|l|}
\hline Samples & Phenolic content & FRAP \\
\hline Teas & & \\
\hline Lipton y & $13.23 \pm 1.17(1)$ & $1.69 \pm 0.07(1)$ \\
\hline Premium & $9.05 \pm 0.09(2)$ & $1.36 \pm 0.0(2)$ \\
\hline Natural tea & $4.84 \pm 0.17(6)$ & $1.30 \pm 0.01(6)$ \\
\hline Conlyl & $8.50 \pm 0.18(3)$ & $1.33 \pm 0.0(3)$ \\
\hline Ginger & $5.54 \pm 1.08(5)$ & $1.32 \pm 0.01(4)$ \\
\hline Pg & $7.36 \pm 1.00(4)$ & $1.310 .01(5)$ \\
\hline Cocoa and Coffee Products & & \\
\hline Concord instant chocolate & $8.523 \pm 2.53(5)$ & $1.63 \pm 0.13(3)$ \\
\hline Blueboat choco & $2.19 \pm 1.07(7)$ & $0.39 \pm 0.03(7)$ \\
\hline Ovaltine & $8.26 \pm 1.12(6)$ & $1.43 \pm 0.02(5)$ \\
\hline Bournvita & $28.93 \pm 4.42(4)$ & $1.56 \pm 0.02(4)$ \\
\hline Nestlemilo & $45.49 \pm 9.14(2)$ & $1.87 \pm 0.04(1)$ \\
\hline Cowbell choco & $38.49 \pm 3.49(3)$ & $1.71 \pm 0.07(2)$ \\
\hline Nescafe & $45.73 \pm 4.02(1)$ & $1.37 \pm 0.00(6)$ \\
\hline Breakfast Cereals & & \\
\hline Jago oats & $0.83 \pm 0.11(7)$ & $\mathrm{ND}$ \\
\hline Quaker oats & $0.58 \pm 0.02(8)$ & $0.33 \pm 0.04(4)$ \\
\hline Weetabix & $2.62 \pm 0.31(5)$ & $0.16 \pm 0.08(6)$ \\
\hline Kellogs & $4.54 \pm 0.24(3)$ & $0.43 \pm 0.08(3)$ \\
\hline Cornflakes & $1.81 \pm 0.11(6)$ & $0.067 \pm 0.03(7)$ \\
\hline Golden morn & $8.41 \pm 0.72(1)$ & $0.26 \pm 0.04(5)$ \\
\hline Cerelac & $3.19 \pm 1.00(4)$ & $0.82 \pm 0.33(2)$ \\
\hline S.Flakes & $5.11 \pm 0.23(2)$ & $1.21 \pm 0.41(1)$ \\
\hline & & \\
\hline
\end{tabular}

Results are presented as Mean \pm Standard Deviation, $\mathrm{n}=3$

( ) = ranking, ND = not detectable

Table 4. Total Phenolic, FRAP and Flavonoid content (mg/g catechin equ.) of fruit pulp (wet weight).

\begin{tabular}{|l|l|l|l|}
\hline Common/native name & Phenolic content & FRAP & Flavonoid content \\
\hline Banana & $0.13 \pm 0.02(8)$ & $0.29 \pm 0.07(4)$ & $0.74 \pm 0.10(6)$ \\
\hline Orange & $0.33 \pm 0.040(5)$ & $0.24 \pm 0.0(6)$ & $0.31 \pm 0.07(8)$ \\
\hline Lime & $0.23 \pm 0.05(7)$ & $0.07 \pm 0.01(9)$ & $0.19 \pm 0.06(9)$ \\
\hline Cucumber & $0.05 \pm 0.0 .05(9)$ & $0.10 \pm 0.01(8)$ & $0.56 \pm 0.09(7)$ \\
\hline Avocado & $0.32 \pm 0.0 .02(6)$ & $0.80 \pm 0.08(1)$ & $2.46 \pm 0.05(3)$ \\
\hline Mango & $0.54 \pm 0.0 .02(3)$ & $0.24 \pm 0.0(5)$ & $0.77 \pm 0.12(5)$ \\
\hline Pineapple & $0.41 \pm 0.14(4)$ & $0.19 \pm 0.01(7)$ & $1.05 \pm 0.09(4)$ \\
\hline Star apple & $3.13 \pm 0.47(1)$ & $0.58 \pm 0.0(2)$ & $3.52 \pm 0.14(1)$ \\
\hline Pawpaw & $0.57 \pm 0.11(2)$ & $0.40 \pm 0.02(3)$ & $3.02 \pm 0.14(2)$ \\
\hline
\end{tabular}

Results are presented as Mean \pm Standard Deviation, $\mathrm{n}=3$

( ) = ranking 
Table 3 presents the Phenolic content, and Ferric Reducing Antioxidant Power (FRAP) (mg/g catechin equ.) of breakfast products. Considering the different classes of breakfast products, the coffee samples have the highest phenolic content followed by the cocoa products then the tea samples. The breakfast cereals tailed the classification. A similar pattern of classification holds when the ferric reducing antioxidant power (FRAP) of the various extracts was measured. The antioxidant capacity (phenolic content) of the Lipton y tea, premium, and conlyl tea were higher than those of Concord instant chocolate, blueboat choco and ovaltine for the cocoa products. A strong correlation was observed between the phenolic content and FRAP of the tea sample $(r=0.890843)$, to an average correlation in the cocoa and tea products $(r=0.59383)$ then to a very weak correlation in the breakfast cereals $(r=0.344098)$ data. This

Table 5. Total Phenolic content, Flavonoid content and Ferric Reducing Antioxidant Power (FRAP) (mg/g catechin equ.) of vegetables and spices

\begin{tabular}{|c|c|c|c|}
\hline Common/native name & Phenolic content & Flavonoid content & FRAP \\
\hline Uha (ora) & $29.30 \pm 2.17(3)$ & $56.49 \pm 8.14(2)$ & $10.01 \pm 0.16(8)$ \\
\hline Green (inine) & $25.75 \pm 3.21(6)$ & $5.40 \pm 1.05(8)$ & $8.08 \pm 0.46(10)$ \\
\hline Ugu (pumpkin leaf) & $27.73 \pm 2.82(5)$ & $40.23 \pm 2.98(4)$ & $10.48 \pm 0.18(7)$ \\
\hline Uziza (Uziza) & $23.13 \pm 0.97(8)$ & $14.18 \pm 3.26(5)$ & $11.81 \pm 0.46(5)$ \\
\hline scent leaf (nchuanwu) & $126.76 \pm 5.20(2)$ & $45.57 \pm 8.93(3)$ & $23.45 \pm 0.11(1)$ \\
\hline bitter leaf (onugbu) & $28.43 \pm 3.93(4)$ & $2.03 \pm 0.17(9)$ & $11.08 \pm 0.04(6)$ \\
\hline $\begin{array}{l}\text { Garden Egg leaf (Akwukwo } \\
\text { anara, afufa) }\end{array}$ & $19.91 \pm 2.43(9)$ & $0.68 \pm 0.17(10)$ & $9.24 \pm 1.32(9)$ \\
\hline Ukazi (ukazi) & $15.70 \pm 0.06(10)$ & $6.02 \pm 0.87(7)$ & $3.28 \pm 1.22(14)$ \\
\hline Onions & $6.13 \pm 0.38(12)$ & ND & $4.15 \pm 0.96(13)$ \\
\hline Garlic & $4.35 \pm 0.89(13)$ & ND & $4.52 \pm 0.57(12)$ \\
\hline Ginger & $10.61 \pm 2.11(11)$ & ND & $14.26 \pm 2.56(3)$ \\
\hline Uda & $23.36 \pm 2.11(7)$ & $7.73 \pm 0.56(6)$ & $14.00 \pm 0.96(4)$ \\
\hline Thyme & $134.55 \pm 4.00(1)$ & $71.44 \pm 8.49(1)$ & $23.09 \pm 0.06(2)$ \\
\hline Fresh pepper & $3.20 \pm 0.44(14)$ & ND & $5.48 \pm 1.01(11)$ \\
\hline
\end{tabular}

Results are presented as Mean \pm Standard Deviation, $\mathrm{n}=3$

$($ ) = ranking; ND = not detectable

Table 6. Total Phenolic and flavonoid content, FRAP (mM catechin equ.) and \% radical scavenging activity of beers and wines

\begin{tabular}{|l|l|l|l|}
\hline $\begin{array}{l}\text { Brand names of beers } \\
\text { and wines }\end{array}$ & Phenolic content & FRAP & Flavonoid content \\
\hline BARON DE TENA & $2865.44 \pm 319.52(4)$ & $252.44 \pm 1.21(4)$ & $2556.44 \pm 683.57(3)$ \\
\hline CASTILLO DE LIRIA & $3988.18 \pm 609.67(2)$ & $261.47 \pm 1.88(2)$ & $2122.12 \pm 267.85(5)$ \\
\hline CUVEE SPECIALE & $3260.25 \pm 356.74(3)$ & $260.67 \pm 3.65(3)$ & $2207.63 \pm 544.79(4)$ \\
\hline RAICES & $4941.27 \pm 278.06(1)$ & $271.63 \pm 2.45(1)$ & $3930.30 \pm 140.01(1)$ \\
\hline VINO TINTO & $2057.32 \pm 194.39(5)$ & $249.38 \pm 1.01(5)$ & $1238.84 \pm 170.49(6)$ \\
\hline STAR & $472.74 \pm 4.90(8)$ & $194.06 \pm 6.33(8)$ & $645.86 \pm 232.65(8)$ \\
\hline SMIRNOFF ICE & $15.51 \pm 5.10(10)$ & $4.07 \pm 4.34(10)$ & $205.91 \pm 121.71(10)$ \\
\hline GUINESS & $1073.66 \pm 131.82(7)$ & $225.59 \pm 2.31(7)$ & $2668.96 \pm 185.64(2)$ \\
\hline GORDON SRARK & $1548.03 \pm 174.79(6)$ & $236.64 \pm 0.37(6)$ & $399.44 \pm 96.51(9)$ \\
\hline GULDER & $434.36 \pm 22.22(9)$ & $174.30 \pm 5.33(9)$ & $669.49 \pm 67.96(7)$ \\
\hline
\end{tabular}

Results are presented as Mean \pm Standard Deviation, $\mathrm{n}=3$

$($ ) = ranking

give an overall correlation of $r=0.60871$ for the phenolic content and FRAP of the breakfast products analyzed. Hence the phenolic content of breakfast products determined by Folin Ciocalteau method may not be directionally propotional to their FRAP. Teas are high in catechins, which are powerful antioxidant compounds capable of scavenging reactive oxygen species. Tea is the most consumed beverage in the world. Scientific studies have shown that regular consumption of teas reduces the incidence of various cancers (Alexis et al., 1999; Balentine et al., 1997; 
Driostic et al., 2001; Steiawan et al., 2001; Wang et al., 2000). Regular tea consumption has equally been reported to inhibit diabetic cataracts in streptozotocin-intoxicated rats (Vinson et al., 2005). Cocoa products are often viewed today as food or snack with little nutritional value. Chocolate (one of cocoa products) ranked third highest daily per capita antioxidant source (Vinson et al., 2006) in the United State of America. Cocoa powder at a human dose equivalent of two dark chocolate bars per day significantly inhibited atherosclerosis, lowered plasma cholesterol, and protected the low density lipoprotein from oxidation (Vinson et al., 2006).

Fruits and vegetables are rich sources of vitamins ( $A, C$ and $E)$, folate, carotenoids and dietary fibers. Fruits and vegetables are also rich in plants phytochemicals including flavonoids (antioxidant phytochemicals). Fruits and vegetables have been associated with prevention of obesity, lowering of plasma cholesterol, which are attributed to their fiber content, and reducing oxidative damage to biological molecules, enhancing immune responses, which are attributed to their antioxidant activity. Earlier studies have indicated that consumption of fruits and vegetables prevent degenerative diseases caused by oxidative stress (Scalbert et al., 2005). Dietary polyphenol intakes from fruits and vegetables are known to reduce the risk of coronary heart disease and cancer (Block et al., 1992). For the analysis of the antioxidant capacity of a variety of fruits consumed in the Eastern Region of Nigeria, three different assay methods (phenolic, FRAP and flavonoid content $\mathrm{mg} / \mathrm{g}$ catechin equ.) were used and results presented in Table 4. Based on the different methods applied the fruits had different antioxidant capacities. Considering the best three fruits of each method, the antioxidant capacity was in the order: star apple > papaw > mango for phenolic content; avocado $>$ star apple > papaw for FRAP; and star apple > papaw > avocado for Flavonoid content. Overall, star apple appear to be the best fruit with high antioxidant capacities, because it appeared first in 2 different methods (Phenolic and flavonoid content) and second in FRAP. Pawpaw comes second because it appeared among the best three in all three methods. Avocado is considered in the third place because it appears among the best three in two methods. Mango which appeared only once (phenolic content) among the best three can be classified fourth. Pearson correlation analysis reveal a close relationship between the results obtained by FRAP and Flavonoid content $(r=0.794539)$ and between the results obtained by Folin (for phenolic content) and Flavonoid content $(r=0.695912)$ but a poor relation between the results of Phenolic content and FRAP $(r=0.444481)$.

The total phenolic content, flavonoid content and FAP of vegetables and spices and their ranking are presented in Table 5. The results of Phenolic and Flavonoid content revealed thyme as the most potent antioxidant followed by scent leaf for phenolic content and uha for flavonoid content whereas fresh pepper was the least followed by garlic and onion. The flavonoid content of onion, garlic, ginger and black pepper was not detectable. Based on FRAP, scent leaf is the most potent antioxidant followed by thyme whereas ukazi had the least antioxidant capacity. Overall, thyme and scent leaf stands out as the samples with the highest antioxidant capacities. The phenolic content of black pepper was far lower than values obtained for black pepper from Cameroon (Agbor et al., 2005; 2006). Regardless of the assay method, the values were all correlated. Between FRAP and Phenolic content $r=0.878466$, 0.778952 for Phenolic content and Flavonoid content, and 0.669312 between FRAP and flavonoid content.

Table 6 presents the total phenolic, flavonoid content, and FRAP (mM catechin equ.) of some alcoholic beverages (beers and wines). Among the alcoholic beverages analyzed, the wines were the most potent compared to beers with the Raices wine standing out (highest antioxidant capacity) and Smirnoff Ice (beer) the least potent irrespective of the method applied. The difference between the antioxidant capacities of wine and beer is that the wines especially red wine are produced from grape which are high in antioxidant compounds such as flavonoids which are transferred to the wine. On the other hand, beers are made from barley, maize, or malt which may not be as rich in antioxidant but rich in starch. Also very little goes to waste in wine making as compared to beer processing. Correlation analysis reveal positive correlation between three methods with the strongest existing between phenolic content and flavonoid content $(r=0.80642)$, then phenolic content and FRAP $(r=0.712918)$ and then FRAP and flavonoids $(r=0.624204)$. Low incidence of cardiovascular events has been associated with moderate wine consumption in spite of a diet high in saturated fat (Renaud and de Lorgeril, 1992). This has been associated with red wine because of its polyphenolic content such as quercetin, myricetin, and catechin (Rice-Evans et al., 1996). These polyphenols extracted from red wines have been shown to protect LDL from oxidation in vitro (Whitehead et al., 1995) and increased plasma antioxidant activity (Aviram, 1996; Maxwell et al., 1994). Red wine and its polyphenol consumption have been reported to significantly reduce LDL-C susceptibility to aggregation in apo $E$ deficient mice compared to placebo (Hayek et al., 1997).

Generally lack of consistency in the correlation between the antioxidant capacity and the polyphenolic contents of natural products have earlier been reported (Agbor et al., 2005). Some authors (Ghiselli et al., 1998; Majo et al., 2008) have found a linear correlation between antioxidant capacity and total polyphenols contents of natural products. Our results are consistent with the claim that statistic correlation is only relevant between total polyphenols and the flavonoids fraction (Katalinic' et al., 2004). We would have expected comparable antioxidant values ranking irrespective of the antioxidant method. But this was not the case in all three methods used for the analysis. The simple reason being that as earlier suggested (Agbor et al., 2005) in all the group of samples analyzed do not contain same kind of substances and the reagents of the methods are different. However, it may be possible to find a strong correlation between methods if the samples are from the same genus and with pure samples as was obtained in the case of wine and teas in the present study. For the other, the plants were from different families, hence the possibility that they contain different chemical constituents, making it difficult to establish a strong correlation. 


\section{Conclusion}

All the samples analyzed showed some antioxidant potentials with coffee being the highest antioxidant source for beverages and scent leaf and thyme highest antioxidant source overall. Thus, vegetables and spices from the eastern region of Nigeria may provide the antioxidant needed from food. A vegetable rich diet and a glass of wine may just be enough antioxidant to keep the body safe from oxidative stress. The results obtained may help guide consumer's choice.

\section{References}

1. Agbor, G.A. (2009). Antioxidant regulation of atherosclerosis: A nutritional stand point. Nutritional Antioxidants in Cancer and Degenerative Diseases, 25-61 ISBN: 978-81-7895-423-3 Editor: E. Olatunde Farombi.

2. Agbor, G.A., Oben, J.E., Ngogang, J.Y., Cai Xinxing, Vinson, J.A. (2005). Antioxidant capacity of some herbs/spices from Cameroon: A comparative study of two methods J. Agric. Food. Chem. 53: 6819-6824.

3. Agbor, G.A., Vinson, J.A., Oben, J.E., Ngogang, J.Y. (2006). Comparative analysis of the in vitro antioxidant activity of white and black pepper. Nutr. Res. 26: 659-663.

4. Agbor, G.A., Vinson, J.A., Oben J.E., Ngogang, J.Y. (2010). Antioxidant Effect of Herbs and Spices on Copper Mediated Oxidation of Lower and Very Low Density Lipoprotein. Chinese Journal of Natural Medicines 8: 0114-0120

5. Alexis, A.F., Jones, V.A., Stiller, M.J. (1999). Potential therapeutic applications of tea in dermatology. Internl. J. Dermatol. 38: 735-743

6. Aviram, M. (1996). Oxidized low density lipoprotein (Ox-LDL) interaction with macrophages in atherosclerosis and the antiatherogenicity of antioxidants. Eur. J. Clin. Chem. Clin. Biochem. 34:599-608.

7. Balentine, D.A., Wiseman, S.A., Bouwens, L.C.M. (1997). The chemistry of tea flavonoids. Crit. Rev. Food Sci. Nutr. 37: 693-704

8. Benzie, I.F.F., Strain, J.J. (1996). The ferric reducing ability of plasma (FRAP) as a measure of "antioxidant power": The FRAP assay. Anal. Biochem. 239: 1-8

9. Block, G., Patterson, B., Subar, A. (1992). Fruits, vegetables and cancer prevention: A review of the epidemiological evidence. Nutr and Cancer, 18: 1-29.

10. Chang, L.W., Yen, W. J., Huang, S. C., Duh, P.D. (2002). Antioxidant activity of sesame coat. Food Chem. 78: 347-354.

11. Clayson, D.B., Mehta, R., Iversin, F. (1994). Oxidative DNA damage-the effects of certain genotoxic and operationally non-genotoxic carcinogens. Mutat. Res.317: 25-42.

12. Collins, A. (2005). Antioxidant intervention as a route to cancer prevention. Eur. J. Cancer. 41: 1923-1930.

13. De Whalley,C.V., Rankin, S.M., Hoult, J.R., Jessup, W., Leake, D.S. (1990). Flavonoids inhibit the oxidative modification of low-density lipoproteins by macrophages. Biochem. Pharmacol. 39: 1743-1750.

14. Dreostic, I.E., Wargovich, M.J., Yang, C.S. (1997). Inhibition of carcinogenesis by tea: the evidence from experimental studies. Critical Review in Food Sci. Nutr. 37: 761-770

15. Farombi, E.O., Britton, G. (1999). Antioxidant activity of palm oil carotenes in organic solution: effects of structure and chemical reactivity. Food Chem. 64: 315- 321.

16. Ghiselli, A., Nardini, M. Baldi, A., Scaccini, C. (1998). Antioxidant activity of different phenolic fractions separated from an Italian red wine. J Agric Food Chem. 46(2): 361-367.

17. Halliwell, B., Gutteridge, J.M.C. (1985). Free radicals ageing and disease, free radicals in biology and medicine. 2nd ed. Oxford, UK: Clarendron Press, p. 279- 315.

18. Hayek, T., Fuhrman, B., Vaya, J., Rosenblat, M., Belinky, P., Coleman, R., Elis, A., Aviram, M. (1997). Reduced progression of atherosclerosis in apolipoprotein Edeficient mice following consumption of red wine, or its polyphenols quercetin or catechin, is associated with reduced susceptibility of LDL to oxidation and aggregation. Arterioscler. Thromb. Vasc Biol. 17(11):2744-52.

19. Hollman, P.C.H., Hertog, M.G.L., Katan, M.B. (1996). Analysis and health effects of flavonoids. Food Chem. 57(1): 43-46.

20. Kalt, W., Dufour, D. (1997). Health functionality of blueberries. HortTechnology, 7: 216-221

21. Katalinic', V., Milos, M., Modun, D., Music', I., Boban, M. (2004). Antioxidant effectiveness of selected wines in comparison wuth (+)-catechin. Food Chem. 86: 593-600.

22. Lee, K.W., Kim, Y.J., Lee, H.J., Lee, C.Y. (2003). Cocoa has more phenolic phytochemicals and a higher antioxidant capacity than teas and red wine. J. Agric. Food Chem. 51: 7292-7295.

23. Lopez, V., Akerreta, S., Casanova, E., Garcia-Mina, J.M., Cavero, R.Y., Calvo, M.I. (2007). In vitro antioxidant and anti-rhizopus activities of lamiaceae herbal extracts. Plant Foods Human Nutr. 62(4): 151-155. 
24. Majo, D.D., Guardia, M.L., Giammanco, S., Neve, L.L., Giammanco, M. (2008). The antioxidant capacity of red wine in relationship with its polyphenolic constituents Food Chem. 111: 45-49

25. Mangiapane, H., Thomson, J., Salter, A., Brown, S., Bell, G.D., White, D.A. (1992). The inhibition of the oxidation of low density lipoprotein by (+)-catechin, a naturally occurring flavonoid. Biochem. Pharmacol. 43(3):445-450

26. Maxwell, S., Cruickshank, A., Thorpe, G. (1994). Red wine and antioxidant activity in serum. Lancet. 344:193-194.

27. Niki, E., Shimaski, H., Mino, M. (1994). Antioxidantism-free radical and biological defense. Gakkai Syuppn Center, Tokyo, 3-16.

28. Puttaraju, N.G., Venkateshaiah, S.U., Dharmesh, S.M., Urs, S.M., Somasundaram, R. (2006). Antioxidant Activity of Indigenous Edible Mushrooms J Agric Food Chem, 54: 9764 -9772

29. Reddy, C.V.K., Sreeramulu, D., Raghunath, M. (2010). Antioxidant activity of fresh and dry fruits commonly consumed in India. Food Res. Intern. 43: 285-288

30. Renaud. S., de Lorgeril, M.. (1992). Wine alcohol, platelets and the French paradox for coronary heart disease. Lancet. 339:1523-1526.

31. Rice-Evans, C.A., Miller, N.J., Paganga, G. (1996). Structure-antioxidant activity relationships of flavonoids and phenolic acids. Free Radic. Biol. Med. 20:933-956.

32. Rimm, E.B., Katan, M.B., Ascherio, A., Stampfer, M.J., Willett, W.C. (1996). Relation between intake of flavonoids and risk for coronary heart disease in male health professionals. Ann. Intern. Med. 125: 384-389

33. Scalbert, A., Manach, C., Morand, C., Remesy, C., Jimenez, L. (2005). Dietary polyphenols and the prevention of Diseases. Crit. Rev. Food Sci. Nutr., 45: 287-306.

34. Setiawan, V.W., Zhang. Z.F., Yu, G.P., Lu, Q.Y., Li, Y.L., Lu, M.L., Wang, M.R., Guo, C.H., Yu, S.Z., Kurtz, R.C., Hsieh, C.C. (2001). Protective effect of green tea on the risks of chronic gastritis and stomach cancer. Int. J. Cancer. 92(4):600-604.

35. Vayalil Praveen K. (2002). Antioxidant and antimutagenic properties of aqueous extract of date fruit (phoenix dactylifera L. Arecaceae). Journal of Agricultural and Food Chemistry, 50(3): 610-617.

36. Vinson, J. A., Yong, A., Xuelci, S., Ligid, Z., Bose, P. (2001). Phenol antioxidant and quantity and quality in foods. J. Agric. Food Chem. 49: 5315-5322.

37. Vinson, J.A., Dabbagh, Y.A., Serry, M.M. (1995b). Plant flavonoids, especially tea flavonoids, are powerful antioxidants using an in vitro oxidation model for heart disease J. Agric. Food Chem. 43(11): 2800-2802.

38. Vinson, J.A., Hao, Y., Su, Xuehui., Zubik, L. (1998). Phenol antioxidant quantity and quality in foods: Vegetables J. Agric. Food Chem. 46(9): 3630-3634

39. Vinson, J.A., Jang, J., Dabbagh, Y.A. (1995a). Plant phenols exhibit lipoprotein-bound antioxidant activity using an in vitro model for heart disease. J. Agric. Food Chem. 43(11): 2798-2799.

40. Vinson. J.A., Proch, J., Bose, P., (2001). Determination of the quantity and quality of polyphenol antioxidants in food and beverages. Methods Enzymol. 335: 103-114.

41. Vinson, J.A., Proch, J., Bose P., Muchler S., Taffera, P., Shuta, D., Samman, N., Agbor, G.A. (2006). Chocolate is a powerful ex vivo and in vivo antioxidant, an antiatherosclerotic agent in an animal model, and a significant contributor to antioxidants in the European and American diets. J. Agric. Food Chem. 54, 8071-8076

42. Vinson, J.A., Zubik, L., Bose, P., Samman, N., Proch, J. (2005). Dried fruits: excellent in vitro and in vivo antioxidants J. Am. Coll. Nutr. 24(1):44-50

43. Wang, H., Provan, G.J., Halliwell, K. (2000). Tea flavonoids: their functions, utilization and analysis. Trends in food Sci. Technol. 11: 152-160

44. Whitehead, T.P., Robinson, D., Allaway, S., Syms, J., Hale, A. (1995). Effect of red wine ingestion on the antioxidant capacity of serum. Clin. Chem. 41:32-35. 